\title{
Inoculation with Nonpathogenic Fusarium solani Increases Severity of Pea Root Rot Caused by Aphanomyces euteiches
}

\author{
R. D. Peters, Agriculture and Agri-Food Canada, Crops and Livestock Research Centre, Charlottetown, PE, Can- \\ ada C1A 4N6; and C. R. Grau, Department of Plant Pathology, University of Wisconsin-Madison, Madison 53706
}

\begin{abstract}
Peters, R. D., and Grau, C. R. 2002. Inoculation with nonpathogenic Fusarium solani increases severity of pea root rot caused by Aphanomyces euteiches. Plant Dis. 86:411-414.

Aphanomyces euteiches is an important root-rotting pathogen of pea. When recovering isolates of A. euteiches from infested soils in Wisconsin using pea as a bait host, isolates of Fusarium solani often were recovered. Experiments were established to compare disease symptoms of pea seedlings inoculated with isolates of $A$. euteiches and $F$. solani alone or in combination. Inoculation of pea seedlings with either of two isolates of A. euteiches produced typical root rot symptoms. However, inoculation of pea seedlings with an isolate of $F$. solani resulted in no disease symptoms, indicating that the isolate was nonpathogenic to pea. Co-inoculation of pea seedlings with $A$. euteiches and the nonpathogenic isolate of $F$. solani resulted in significantly $(P=0.05)$ greater disease severity than inoculation with $A$. euteiches alone. Both A. euteiches and F. solani could be reisolated, individually or together, from pea seedlings following individual or coinoculations, respectively. Although the mechanisms of interaction between these two species are unknown, the synergism documented in this study indicates that the interactions of pathogens with nonpathogens may affect development of disease symptoms.
\end{abstract}

Additional keywords: Aphanomyces root rot, pathogen interaction, Pisum sativum

\begin{abstract}
Aphanomyces euteiches Drechs. is an important soilborne plant pathogen causing root rot and seedling blight of a number of economically important crops, including pea, alfalfa, and bean $(8,14,20,23)$. Pathogenic variation in $A$. euteiches has been reported at both the host species $(11,13)$ and cultivar (11) levels, leading to the description of host-specific pathotypes and virulence phenotypes of the pathogen, respectively.

Isolates of A. euteiches are routinely recovered from soil using pea as a bait host (20). In subsequent isolations from pea tissues using a semiselective medium (26), Fusarium spp. often were recovered in addition to $A$. euteiches. In particular, Fusarium solani was frequently isolated from pea bait hosts growing in a variety of Wisconsin soils (unpublished data). Isolates of $F$. solani pathogenic to pea are commonly referred to as $F$. solani (Mart.) Sacc. f. sp. pisi (F. R. Jones) W. C. Snyder \& H. N. Hans. and cause a dry root rot of
\end{abstract}

Corresponding author: R. D. Peters

E-mail: petersr@em.agr.ca

AAFC Contribution No. 982.

Accepted for publication 16 December 2001.

Publication no. D-2002-0218-01R

This article is in the public domain and not copyrightable. It may be freely reprinted with customary crediting of the source. The American Phytopathological Society, 2002. economic importance (15). However, isolates of $F$. solani in mating population VI, which includes those isolates pathogenic to pea, are extremely diverse. Isolates in this population can exist saprophytically in the soil, cause disease on nine different plant species, or be associated with diseased plant tissue of several plant species of which they are not primary pathogens $(10,35)$. In addition, isolates of $F$. solani $\mathrm{f}$. sp. pisi vary widely in pathogenicity, and nonpathogenic strains of $F$. solani have been found on pea (5).

Few studies have examined the effects of the interaction of A. euteiches with other microorganisms on severity of pea diseases. Disease severity caused by A. euteiches was shown to increase in plants infected with viruses (4) or exposed to Pratylenchus penetrans (25), but was not affected by the addition of Pythium spp. to soil (1). Although A. euteiches and F. solani are commonly found together in field soils (6), past investigations have concentrated on disease caused by inoculations with each of these microorganisms separately and not on interactions between them.

Given the frequency of isolation of $F$. solani from pea seedlings used as bait hosts for A. euteiches in our lab, studies were initiated to examine the interaction of $A$. euteiches and $F$. solani in pea seedlings. In particular, the impact of the presence of both organisms in pea on the expression of disease symptoms was investigated.

\section{MATERIALS AND METHODS}

Fungal isolates. The isolate of $F$. solani used in inoculation studies was recovered from a sandy soil (collected in Hancock, WI) during routine screening for the presence of A. euteiches using pea (cv. 77 Early Perfection) as a bait host (20). Twocentimeter lengths of basal stem (measured up the stem from the soil surface) were cut from 10 pea plants with a sterile scalpel, surface sterilized in $10 \%$ Clorox $(0.6 \%$ sodium hypochlorite) for $2 \mathrm{~min}$, rinsed twice in sterile distilled water, and blotted dry on sterile filter paper (Whatman No. 4). Stem pieces then were cut longitudinally with a sterile scalpel and plated (internal surface touching medium) onto corn meal agar (CMA; Difco Laboratories, Detroit) in small petri dishes (60 by 15 mm; Fisher Scientific Co., Nepean, Ontario, Canada). Petri dishes were incubated in the dark at $22^{\circ} \mathrm{C}$ for 3 to 4 days. Following incubation, hyphal tips from the margins of actively growing cultures were removed with a sterile dissecting needle and plated onto CMA to generate pure cultures. A single spore plucked from a pure culture (selected at random) with an agar-tipped dissecting needle was plated onto CMA to generate a single-spore isolate, Fs01, which was characterized as $F$. solani according to the key of Nelson et al. (24).

A semiselective medium was used to isolate A. euteiches from pea and bean roots showing symptoms of Aphanomyces root rot (26). Isolates were characterized as A. euteiches according to the descriptions of Dick (9) and Scott (31). An isolate of $A$. euteiches from pea (P54) and an isolate from bean (B16) were used to represent isolates from different host origins and host preferences (pathotypes) as determined by pathogenicity tests and phenotypic comparisons (19). Isolates of $\mathrm{A}$. euteiches and $F$. solani were maintained on CMA at $12^{\circ} \mathrm{C}$ and transferred to fresh CMA at 6-month intervals.

Inoculation trials. Pea cv. 77 Early Perfection (77EP) and breeding line MN313 were used for inoculation trials. 77EP is highly susceptible to A. euteiches, whereas MN313 has shown resistance to specific pathotypes of the pathogen (20). Pea seeds were scarified with a razor blade and then sown at a 3-cm depth in approximately 200 $\mathrm{cm}^{3}$ of moistened vermiculite (Holiday, medium grade; VIL Vermiculite Inc., Toronto, Ontario, Canada) in waxed paper 
cups. Approximately $0.1 \mathrm{~g}$ of Rhizobium leguminosarum inoculum (pea strain, $\mathrm{Ni}$ tragin Inoculants; Liphatech Inc., Milwaukee, WI ) was added prior to covering each seed. Cups were placed in a growth room at $25^{\circ} \mathrm{C}$ (12-h day length) and watered daily prior to inoculation.

Pea seedlings were flooded with deionized water and inoculated 7 days after planting. Zoospores of $A$. euteiches were produced using the method described by Mitchell and Yang (22). A 1-ml sample of zoospores was immobilized by vigorous vortexing (15 s) and counted with a hemacytometer to standardize inoculum to $1 \times 10^{3}$ zoospores $/ \mathrm{ml}$. The inoculum (10 $\mathrm{ml}, 1 \times 10^{4}$ zoospores) was dispensed at the base of the seedling in each flooded cup using a sterile pipette. A spore suspension of $F$. solani isolate Fs01 was prepared by flooding 2 -week-old agar cultures with sterile deionized water, scraping the surface of each plate with a rubber policeman, and decanting the resulting suspension into a beaker. With the aid of a hemacytometer, the concentration of inoculum was standardized to $1 \times 10^{4}$ microconidia/ml with sterile deionized water. Ten milliliters of the inoculum $\left(1 \times 10^{5}\right.$ microconidia $)$ was dispensed at the base of the seedling in each flooded cup using a sterile pipette directly following inoculation with $\mathrm{A}$. $\mathrm{eu}$ teiches. Noninoculated control plants received sterile deionized water only.

Water was drained from the paper cups containing the pea seedlings 5 days after

Table 1. Mean disease severity of pea cv. 77 Early Perfection inoculated separately and together with Aphanomyces euteiches (isolate P54) and Fusarium solani (isolate Fs01)y

\begin{tabular}{lc}
\hline Isolate & $\begin{array}{c}\text { Mean } \\
\text { DSI }^{\mathbf{z}}\end{array}$ \\
\hline A. euteiches P54 + F. solani $\mathrm{Fs} 01$ & $4.4 \mathrm{a}$ \\
A. euteiches $\mathrm{P} 54$ & $3.7 \mathrm{~b}$ \\
F. solani $\mathrm{Fs} 01$ & $1.0 \mathrm{c}$ \\
Control & $1.0 \mathrm{c}$ \\
\hline
\end{tabular}

${ }^{\mathrm{y}}$ Isolates of A. euteiches (P54) and F. solani (Fs01) were obtained from pea. Pea seedlings growing in moistened vermiculite in a growth room at $25^{\circ} \mathrm{C}$ (12-h day length) were flooded with deionized water and inoculated 7 days after planting with $1 \times 10^{4}$ zoospores of $A$. euteiches immediately followed by inoculation with $1 \times 10^{5}$ microconidia of $F$. solani. Uninoculated control plants received sterile deionized water only. Fourteen days after inoculation, the inoculated seedlings were carefully removed, washed, and evaluated for disease severity.

${ }^{\mathrm{z}}$ DSI $=$ disease severity index: $1=$ no discoloration of roots; $2=$ slight necrosis of roots; 3 $=$ necrosis of roots and lower epicotyl; $4=$ extensive necrosis of roots and epicotyl, foliar chlorosis/necrosis; $5=$ dead seedling. Means are based on the pooled data from two experiments each with four replicates and six pea seedlings evaluated per replicate. Means followed by the same letter are not significantly different $(P=0.05)$ based on a protected test of least significant difference (LSD $=0.51$ ). inoculation. Plants then were watered daily beginning 6 days after inoculation. At 7 days after inoculation ( 2 weeks after planting), pea plants were fertilized with halfstrength Hoagland's solution (12) delivered with a watering can. At 14 days after inoculation, the inoculated seedling was carefully removed from each cup, washed, and evaluated for disease severity using the following disease severity index (DSI): $1=$ no discoloration of roots; 2 = slight necrosis of roots; $3=$ necrosis of roots and lower epicotyl; $4=$ extensive necrosis of roots and epicotyl, foliar chlorosis or necrosis; and $5=$ dead seedling. Following rating, approximately $2 \mathrm{~cm}$ of the basal stem was excised from each seedling, surface sterilized in $10 \%$ Clorox, and plated onto CMA as described previously, to isolate fungi from the basal stem tissues.

Inoculation studies were conducted as a set of three experiments. Each experiment was repeated. Experiment 1 examined the response of pea cv. 77EP to separate and co-inoculation with isolate P54 of A. euteiches and isolate Fs01 of $F$. solani, and was arranged as a completely randomized design with four replicates and six seedlings/replicate. Experiment 2 examined the response of two pea genotypes, 77EP and MN313, to separate and co-inoculation with isolates P54 and Fs01, and was arranged as a randomized complete block design with three replicates and four seedlings/replicate. Experiment 3 examined the response of pea genotypes 77EP and MN313 to separate and co-inoculation with isolate $\mathrm{B} 16$ of $A$. euteiches and isolate Fs01, and was arranged as a randomized complete block design with four replicates and four seedlings/replicate.

Data analysis. Data for DSI values were analyzed by analysis of variance (Genstat
5, Release 3[1], The Numerical Algorithms Group Ltd., Oxford, UK). If a significant treatment effect was found, the test of least significant difference (LSD, $P=0.05$ ) was used to separate treatment means. Data for repeated experiments were pooled following tests for homogeneity of variance and the absence of significant interactions of the repeated experiments with main effects (pea genotypes and inoculation treatments) or with interaction terms. Main effect means of pea genotype response to infection with multiple isolates were compared when cultivar-isolate interactions were not significant.

\section{RESULTS}

Inoculation of pea with fungal isolates resulted in development of root rot symptoms that could be measured 2 weeks after inoculation. Conversely, noninoculated control plants remained healthy. In experiment 1, co-inoculation of pea with $\mathrm{A}$. euteiches (P54) and $F$. solani $(\mathrm{Fs} 01)$ resulted in significantly $(P=0.05)$ more disease than inoculation with P54 or Fs01 alone (Table 1). Inoculation of pea with Fs01 alone resulted in no disease symptoms, similar to results with the control treatment (Table 1).

Results for experiment 2 were similar to those of experiment 1. Cultivar-isolate interactions were not significant; therefore, treatment means for main effects were compared using LSD values. Both pea genotypes (77EP and MN313) responded similarly to infection with P54 (main effect of pea genotypes was not significant in the analysis of variance; Table 2). Coinoculation of pea with P54 and Fs01 resulted in significantly more disease $(P=$ $0.05)$ than inoculation with P54 or Fs01 alone (Table 2). Inoculation of pea with

Table 2. Mean disease severity of pea seedlings (cv. 77 Early Perfection and MN313) inoculated separately and together with Aphanomyces euteiches (isolate P54) and Fusarium solani (isolate Fs01) ${ }^{\mathrm{x}}$

\begin{tabular}{lccc}
\hline & \multicolumn{2}{c}{ Pea genotype } & \\
\cline { 2 - 3 } Isolate & Cv. 77 Early Perfection & Breeding line MN313 & Mean $^{\mathbf{y}}$ \\
\hline A. euteiches P54 +F. solani Fs01 & 4.3 & 4.3 & $4.3 \mathrm{a}$ \\
A. euteiches P54 & 3.7 & 3.9 & $3.8 \mathrm{~b}$ \\
F. solani Fs01 & 1.0 & 1.0 & $1.0 \mathrm{c}$ \\
Control & 1.0 & 1.0 & $1.0 \mathrm{c}$ \\
Mean $^{z}$ & $2.5 \mathrm{a}$ & $2.5 \mathrm{a}$ & $\ldots$ \\
\hline
\end{tabular}

${ }^{x}$ Isolates of $A$. euteiches (P54) and F. solani (Fs01) were obtained from pea. Pea cv. 77 Early Perfection and breeding line MN313 were used as plant hosts for inoculation. Pea cv. 77EP is highly susceptible to infection by A. euteiches whereas MN313 has shown resistance to specific pathotypes of the pathogen. Pea seedlings growing in moistened vermiculite in a growth room at $25^{\circ} \mathrm{C}$ (12-h day length) were flooded with de-ionized water and inoculated 7 days after planting with $1 \times$ $10^{4}$ zoospores of $A$. euteiches immediately followed by inoculation with $1 \times 10^{5}$ microconidia of $F$. solani. Uninoculated control plants received sterile deionized water only. Fourteen days after inoculation, the inoculated seedlings were carefully removed, washed, and evaluated for disease severity. Disease severity index: $1=$ no discoloration of roots; $2=$ slight necrosis of roots; $3=$ necrosis of roots and lower epicotyl; 4 = extensive necrosis of roots and epicotyl, foliar chlorosis/necrosis; 5 = dead seedling. Means are based on the pooled data from two experiments each with three replicates and four pea seedlings evaluated per replicate.

y Column means followed by the same letter are not significantly different $(P=0.05)$ based on a protected test of least significant difference $(\mathrm{LSD}=0.33)$.

${ }^{\mathrm{z}}$ Means followed by the same letter are not significantly different $(P=0.05)$ based on a protected test of least significant difference $(\mathrm{LSD}=0.24)$. 
Fs01 alone resulted in no disease symptoms.

Inoculation of pea genotypes 77EP and MN313 with isolates B16 and Fs01 resulted in significant cultivar-isolate interactions $(P<0.001)$. Inoculation with isolate $\mathrm{B} 16$ alone caused disease in 77EP, but not in MN313 (Table 3). Inoculation with Fs01 alone did not result in disease development in either pea genotype. However, co-inoculation of 77EP with B16 and Fs01 resulted in significantly more disease $(P=$ $0.05)$ than inoculation with B16 alone (Table 3). MN313 expressed mild symptoms (mean DSI $=1.3$ ) when co-inoculated with B16 and Fs01 (Table 3).

In all three experiments, attempts to reisolate $A$. euteiches and $F$. solani from pea seedlings inoculated separately with these organisms were successful. Isolation attempts from pea co-inoculated with $A$. euteiches and $F$. solani yielded both organisms, which were readily distinguished on agar plates by growth rate and culture morphology.

\section{DISCUSSION}

Inoculation of pea seedlings with $A$. $e u$ teiches resulted in development of symptoms typical of Aphanomyces root rot, whereas inoculation with $F$. solani alone produced no visible symptoms of disease. The isolate of $F$. solani used in this study was, therefore, nonpathogenic to pea. However, co-inoculation of pea seedlings with $A$. euteiches and the nonpathogenic isolate of $F$. solani resulted in greater disease severity than inoculation with $\mathrm{A}$. $\mathrm{eu}$ teiches alone. This phenomenon occurred in two different pea cultivars and with two different isolates of $A$. euteiches. Reisolation from stem tissues indicated that $A$. euteiches and $F$. solani could colonize host tissues and coexist in infected stems.

The colonization of plant tissues by nonpathogenic microorganisms, endophytes, and microorganisms antagonistic to specific pathogens is a strategy that has been successfully employed to reduce disease. For example, applications of nonpathogenic isolates of $F$. oxysporum have been found to be efficacious in the biocontrol of Fusarium diseases of cucumber (21), tomato (3), and flax (17). Endophytic fungi found in grasses have been shown to confer resistance to fungal diseases (2). The presence of beneficial endophytic bacteria in crops has been associated with increased resistance to diseases and other plant stresses (32). The mechanisms of disease suppression of bacterial or fungal agents found within host tissues include direct antagonism of specific pathogens, colonization of host tissue and niche exclusion, direct competition for resources, and elicitation of defense responses in the host.

Although research emphasis has been placed on microorganism interactions that reduce disease, synergistic interactions which increase disease development have also been documented. The synergistic interaction of Pratylenchus penetrans and Verticillium dahliae causing early dying disease of potato is well known $(18,30)$. Rot of potato tubers infected with Phytophthora infestans was visibly accelerated by secondary infection with $F$. sambucinum and $F$. solani (16). Instances of synergistic interactions between pathogens often occur when one pathogen provides a pathway for infection or alters the host substrate in favor of the secondary or "weaker" pathogen. It has been postulated that the $V$. dahliae-Pratylenchus penetrans synergism is the result of the enhanced pathogenesis of $V$. dahliae in the presence of the nematode (29). Alteration of plant physiology, particularly a reduction in gas exchange, in the presence of both organisms has been documented (30). In our study, the isolate of $F$. solani evaluated was nonpathogenic to pea, but colonized pea stems. Possible

Table 3. Mean disease severity of peas (cv. 77 Early Perfection and MN313) inoculated separately and together with Aphanomyces euteiches (isolate B16) and Fusarium solani (isolate Fs01) ${ }^{\mathrm{y}}$

\begin{tabular}{lcc}
\hline & \multicolumn{2}{c}{ Pea genotype $^{\mathbf{z}}$} \\
\cline { 2 - 3 } Isolate & Cv. 77 Early Perfection & Breeding line MN313 \\
\hline A. euteiches $\mathrm{B} 16+$ F. solani & $3.9 \mathrm{a}$ & $1.3 \mathrm{a}$ \\
Fs01 & $3.6 \mathrm{~b}$ & $1.0 \mathrm{~b}$ \\
A. euteiches $\mathrm{B} 16$ & $1.0 \mathrm{c}$ & $1.1 \mathrm{~b}$ \\
F. solani Fs01 & $1.0 \mathrm{c}$ & $1.0 \mathrm{~b}$ \\
Control &
\end{tabular}

y Isolates of A. euteiches (B16) and F. solani (Fs01) were obtained from bean and pea, respectively. Pea cv. 77 Early Perfection and breeding line MN313 were used as plant hosts for inoculation. Pea cv. 77EP is highly susceptible to infection by A. euteiches whereas MN313 has shown resistance to specific pathotypes of the pathogen. Pea seedlings growing in moistened vermiculite in a growth room at $25^{\circ} \mathrm{C}$ (12-h day length) were flooded with deionized water and inoculated 7 days after planting with $1 \times 10^{4}$ zoospores of A. euteiches immediately followed by inoculation with $1 \times 10^{5}$ microconidia of $F$. solani. Uninoculated control plants received sterile deionized water only. Fourteen days after inoculation, the inoculated seedlings were carefully removed, washed, and evaluated for disease severity. Disease severity index: $1=$ no discoloration of roots; $2=$ slight necrosis of roots; 3 = necrosis of roots and lower epicotyl; $4=$ extensive necrosis of roots and epicotyl, foliar chlorosis/necrosis; 5 = dead seedling. Means are based on the pooled data from two experiments each with four replicates and four pea seedlings evaluated per replicate.

${ }^{\mathrm{z}}$ Column means followed by the same letter are not significantly different $(P=0.05)$ based on a protected test of least significant difference $(\mathrm{LSD}=0.24)$. mechanisms responsible for the synergy following co-inoculation of pea seedlings with $A$. euteiches and $F$. solani require further study, including the possibility of enhanced pathogenesis of A. euteiches in the presence of nonpathogenic $F$. solani, the alteration of plant physiology, or the activation of $F$. solani as an opportunist.

One hypothesis for the observed synergism is stimulation of phytoalexin production by the host plant. Infection of pea by $A$. euteiches or $F$. solani elicits the production of the phytoalexin pisatin in host tissues. Pisatin reaches high levels in pea tissue infected by A. euteiches (27). Isolates of A. euteiches have been shown to be inhibited by pisatin in vitro $(28,34)$, yet high concentrations of pisatin in pea tissues do not restrict the pathogen in vivo $(27,28)$. Incorporation of polar lipid extracts from pea into an artificial growth medium decreased the pisatin sensitivity of A. euteiches in vitro (33), which may explain the low sensitivity of $A$. euteiches in vivo. Isolates of $F$. solani also stimulate pisatin production in pea (7). Nonpathogenic isolates of $F$. solani induced high quantities of pisatin more quickly than pathogenic clones. Isolates of $F$. solani virulent to pea were tolerant of pisatin, and excelled at degrading (7) or demethylating (36) pisatin. In contrast, isolates of F. solani most sensitive to pisatin lacked the ability to demethylate pisatin, and had low virulence to pea (36).

Based on the reported effects of pathogen infection on pisatin accumulation in pea, we hypothesize that the observed synergism between $A$. euteiches and a nonpathogenic isolate of $F$. solani may be related to elicitation and concentration of pisatin in the host. Infection of pea tissue by $A$. euteiches induces pisatin production. As colonization of the host proceeds, pisatin concentration increases with the severity of symptoms. A pathogenic isolate of $F$. solani would induce the host to produce pisatin at a slower rate than a nonpathogenic form, and would eventually reduce pisatin concentration by demethylation. Thus, a pathogenic isolate of $F$. solani would not interact synergistically with $A$. euteiches because pisatin levels would decline. However, a nonpathogenic isolate of $F$. solani would colonize host tissues without causing symptoms, induce the host to produce pisatin, and is incapable of degrading pisatin. When A. euteiches and nonpathogenic $F$. solani occur together on pea, pisatin concentration is probably higher than when induced by infection with A. euteiches alone. High concentrations of pisatin favor pathogenicity of A. euteiches, resulting in greater severity of symptoms compared with infection with A. euteiches alone. Although most published work attempts to relate pisatin production to host resistance to pathogens, our results suggest that pisatin may be involved in, or required for, pathogenesis by A. euteiches. 


\section{ACKNOWLEDGMENTS}

We thank N. Kurtzweil for technical assistance.

\section{LITERATURE CITED}

1. Alconero, R., and Hagedorn, D. J. 1967. Pythium relationships to Aphanomyces root rot of peas. Phytopathology 57:1394-1395.

2. Bacon, C. W., Richardson, M. D., and White, J. F., Jr. 1997. Modification and uses of endophyte-enhanced turfgrasses: A role for molecular technology. Crop Sci. 37:1415-1425.

3. Bao, J. R., and Lazarovits, G. 2001. Differential colonization of tomato roots by nonpathogenic and pathogenic Fusarium oxysporum strains may influence Fusarium wilt control. Phytopathology 91:449-456.

4. Beute, M. K., and Lockwood, J. L. 1968. Mechanism of increased root rot in virusinfected peas. Phytopathology 58:1643-1651.

5. Bolton, A. T., Donaldson, A. G., and Nuttall, V. W. 1970. Variation in isolates of Fusarium solani f. sp. pisi collected from processing peas in Ontario. Can. Plant Dis. Surv. 50:108109.

6. Burke, D. W., Hagedorn, D. J., and Mitchell, J. E. 1969. Aphanomyces and Fusarium root rot of peas with partial vs. total exposure of roots to infested soil. Phytopathology 59:1261-1266

7. Christenson, J. A., and Hadwiger, L. A. 1973. Induction of pisatin formation in the pea foot region by pathogenic and nonpathogenic clones of Fusarium solani. Phytopathology 63:784-790.

8. Delwiche, P. A., Grau, C. R., Holub, E. B., and Perry, J. B. 1987. Characterization of Aphanomyces euteiches isolates recovered form alfalfa in Wisconsin. Plant Dis. 71:155161.

9. Dick, M. W. 1971. Oospore structure in Aphanomyces. Mycologia 63:686-688.

10. Funnell, D. L., Matthews, P. S., and VanEtten, H. D. 2001. Breeding for highly fertile isolates of Nectria haematococca MPVI that are highly virulent on pea and in planta selection for virulent recombinants. Phytopathology 91:92-101.

11. Grau, C. R., Muehlchen, A. M., Tofte, J. E., and Smith, R. R. 1991. Variability in virulence of Aphanomyces euteiches. Plant Dis. 75:1153-1156.

12. Hoagland, D. R., and Arnon, D. I. 1938. The water-culture method for growing plants without soil. Univ. Calif. Berkeley Agric. Exp.
Exp. Stn. Circ. 347:1-32.

13. Holub, E. B., Grau, C. R., and Parke, J. L. 1991. Evaluation of the forma specialis concept in Aphanomyces euteiches. Mycol. Res. 95:147-157.

14. Jones, F. R., and Drechsler, C. 1925. Root rot of peas in the United States caused by Aphanomyces euteiches. J. Agric. Res. 30:293-325.

15. Kraft, J. M., Burke, D. W., and Haglund, W. A. 1981. Fusarium diseases of beans, peas and lentils. Pages 142-156 in: Fusarium: Diseases, Biology, and Taxonomy. P. E. Nelson, T. A. Toussoun, and R. J. Cook, eds. Pennsylvania State University Press, University Park

16. Lambert, D. H., and Currier, A. I. 1997. Differences in tuber rot development for North American clones of Phytophthora infestans. Am. Potato J. 74:39-43.

17. Lemanceau, P., and Alabouvette, C. 1991. Biological control of Fusarium diseases by fluorescent Pseudomonas and non-pathogenic Fusarium. Crop Prot. 10:279-286.

18. MacGuidwin, A. E., and Rouse, D. I. 1990. Role of Pratylenchus penetrans in the potato early dying disease of Russet Burbank potato. Phytopathology 80:1077-1082.

19. Malvick, D. K., Grau, C. R., and Percich, J. A. 1998. Characterization of Aphanomyces euteiches strains based on pathogenicity tests and random amplified polymorphic DNA analyses. Mycol. Res. 102:465-475.

20. Malvick, D. K., and Percich, J. A. 1998. Variation in pathogenicity and genotype among single-zoospore strains of Aphanomyces euteiches. Phytopathology 88:52-57.

21. Mandeel, Q., and Baker, R. 1991. Mechanisms involved in biological control of Fusarium wilt of cucumber with strains of nonpathogenic Fusarium oxysporum. Phytopathology 81:462-469.

22. Mitchell, J. E., and Yang, C. Y. 1966. Factors affecting the growth and development of Aphanomyces euteiches. Phytopathology 56:917-922.

23. Munkvold, G. P., Carlton, W. M., Brummer, E. C., Meyer, J. R., Undersander, D. J., and Grau, C. R. 2001. Virulence of Aphanomyces euteiches isolates from Iowa and Wisconsin and benefits of resistance to A. euteiches in alfalfa cultivars. Plant Dis. 85:328-333.

24. Nelson, P. E., Toussoun, T. A., and Marasas, W. F. O. 1983. Fusarium Species. An Illus- trated Manual for Identification. Pennsylvania State University Press, University Park.

25. Oyekan, P. O., and Mitchell, J. E. 1972. The role of Pratylenchus penetrans in the root rot complex of canning pea. Phytopathology 62:369-373.

26. Pfender, W. F., Delwiche, P. A., Grau, C. R. and Hagedorn, D. J. 1984. A medium to enhance recovery of Aphanomyces from infected plant tissue. Plant Dis. 68:845-847.

27. Pueppke, S. G., and VanEtten, H. D. 1974. Pisatin accumulation and lesion development in peas infected with Aphanomyces euteiches, Fusarium solani f. sp. pisi, or Rhizoctonia solani. Phytopathology 64:1433-1440.

28. Pueppke, S. G., and VanEtten, H. D. 1976. The relation between pisatin and the development of Aphanomyces euteiches in diseased Pisum sativum. Phytopathology 66:11741185

29. Riedel, R. M., and Rowe, R. C. 1985. Lesion nematode involvement in potato early dying disease. Am. Potato J. 62:163-171.

30. Saeed, I. A. M., MacGuidwin, A. E., and Rouse, D. I. 1987. Synergism of Pratylenchus penetrans and Verticillium dahliae manifested by reduced gas exchange in potato. Phytopathology 87:435-439.

31. Scott, W. W. 1961. A Monograph of the Genus Aphanomyces. Virginia Agricultural Experiment Station, Blacksburg, VA.

32. Sturz, A. V., Christie, B. R., and Nowak, J. 2000. Bacterial endophytes: Potential role in developing sustainable systems of crop production. Crit. Rev. Plant Sci. 19:1-30.

33. Sweigard, J., and VanEtten, H. D. 1987. Reduction in pisatin sensitivity of Aphanomyces euteiches by polar lipid extracts. Phytopathology 77:771-775.

34. VanEtten, H. D. 1973. Differential sensitivity of fungi to pisatin and to phaseolin. Phytopathology 63:1477-1482.

35. VanEtten, H. D., and Kistler, H. C. 1988. Nectria haematococca, mating populations I and VI. Pages 190-206 in: Advances in Plan Pathology. Vol. 6. Genetics of Plant Pathogenic Fungi. G. S. Sidhu, ed. Academic Press, New York.

36. VanEtten, H. D., Matthews, P. S., Tegtmeier, K. J., Dietert, M. F., and Stein, J. I. 1980. The association of pisatin tolerance and demethylation with virulence on pea in Nectria haematococca. Physiol. Plant Pathol. 16:257268. 